\title{
Ação da Própolis sobre a Desaminação de Aminoácidos e a Fermentação Ruminal ${ }^{1}$ \\ Deolindo Stradiotti Júnior², Augusto Cesar de Queiroz ${ }^{3}$, Rogério de Paula Lana ${ }^{3}$, Cristiana Gama Pacheco ${ }^{4}$, Eduardo da Costa Eifert ${ }^{5}$, Poliana Mary Magalhães Nunes ${ }^{6}$
}

\begin{abstract}
RESUMO - Foram objetivos deste trabalho determinar a ação in vitro da própolis sobre a atividade específica de produção de amônia (AEPA) ou atividade de desaminação de aminoácidos e sobre a fermentação ruminal em bovinos. A AEPA foi determinada utilizando-se líquido de rúmen e tampão de McDougall (1:4) contendo diferentes níveis de extrato de própolis e excesso de caseína hidrolisada. No estudo da ação da própolis in vivo sobre a fermentação ruminal e AEPA, foram utilizados quatro novilhos Holandeses, em dois períodos experimentais, sob dieta contendo 35\% de concentrado, submetidos aos tratamentos controle e com extrato de própolis. O extrato de própolis obtido com etanol a 70\% em água foi mais eficiente in vitro que a 99,5\%, obtendo-se valores de até 78\% de inibição da AEPA em relação ao controle. O extrato de própolis não afetou o consumo de matéria seca, o pH ruminal, as concentrações de amônia e de proteína microbiana e as proporções molares dos ácidos graxos voláteis (AGV), acético, propiônico e butírico no líquido de rúmen. Entretanto, o extrato de própolis aumentou a concentração de AGV totais e inibiu a AEPA pelos microrganismos ruminais, indicando que, apesar de não ter reduzido o nível ruminal de amônia, existe o potencial deste efeito ocorrer em outras situações, como em dietas contendo alta taxa de proteína degradável/carboidrato fermentescível, observado em pastagens novas de gramíneas ou pastagens de gramíneas consorciadas com leguminosas.
\end{abstract}

Palavras-chave: AGV, amônia, fermentação ruminal, pH, proteína

\section{Effect of the Propolis on Amino Acids Deamination and Ruminal Fermentation}

\begin{abstract}
The objective of this work was to determine the in vitro effect of the propolis on the specific activity of ammonia production (SAAP) or activity deamination of amino acids and on ruminal fermentation in bovine. The SAAP was determined using ruminal fluid and McDougall buffer (1:4) with different levels of propolis extract and excess of hydrolyzed casein. In the study of the in vitro effect of the propolis on the ruminal fermentation and SAAP, four Holstein steers were used, in two experimental periods, fed a 35.0\% concentrate diet and submitted to the control and propolis extract treatments. The propolis extract obtained with ethanol at $70 \%$ in water was in vitro more efficient than that obtained with ethanol at $99.5 \%$ in water. Values up to $78 \%$ of SAAP inhibition in relation to the control were obtained. The propolis extract did not affect dry matter intake, ruminal pH, ammonia and microbial protein concentrations. There were no differences for molar proportions of the volatile fat acid (VFA), acetic, propionic and butyric in the rumen fluid. However, the propolis extract increased the total VFA concentration as well as inhibited SAAP by the ruminal microorganisms, demonstrating that, in spite of not having reduced the ruminal ammonia level, it seems to exist potential of this effect to happen in other situations, as in diets with high rate of degradable protein/fermentable carbohydrate, observed in new grass pastures or grass pastures consociated with legumes.
\end{abstract}

Key Words: ammonia, $\mathrm{pH}$, protein, ruminal fermentation, VFA

\section{Introdução}

Nas últimas três décadas, a pecuária bovina brasileira tem sofrido um estreitamento na relação benefício/custo, em parte, resultado da competitividade de outros mercados. Diante dessa realidade, fica a certeza de não mais haver espaço para improvisações e descuidos na bovinocultura. Em todas as etapas, a eficiência deve presidir o processo produtivo, não só pela observância de aspectos do mercado consumidor, mas também pelo respeito aos detalhes técnicos, como os relativos ao manejo e à alimentação dos animais.

Entre as exigências impostas pelos mercados importadores dos produtos de origem bovina, a obser-

\footnotetext{
${ }^{1}$ Parte da tese de Doutorado do primeiro autor, parcialmente financiada pelo CNPq.

2 Zootecnista, DS em Nutrição de Rumiantes - DZO/UFV; Professor Titular de Nutrição Animal, IESES - Instituto de Ensino Superior do Espírito Santo - Faculdade Castelo - ES. E.mail: jrstradiotti@terra.com.br

3 Professor do Departamento de Zootecnia da Universidade Federal de Viçosa, Viçosa-MG, 36571-000; Bolsista do CNPq.

${ }^{4}$ Bióloga, Professora do Departamento de Ciências Agrárias, IESES - Instituto de Ensino Superior do Espírito Santo - Faculdade Castelo - ES.

${ }^{5}$ Doutor em Nutrição de Ruminantes - DZO/UFV.

${ }^{6}$ Mestre em Zootecnia - DZO/UFV.
} 
vância de que os animais tenham sido alimentados com rações isentas de antibióticos aditivos e promotores de crescimento é considerada de suma importância. Este tipo de exigência também é observado no mercado interno por intermédio de movimentos de associações de consumidores. Logo, a busca e utilização de aditivos naturais que possam suprir, ao menos em equivalência, o uso desses antibióticos no quesito produtividade constituem importante diferencial de qualidade, por isentarem os produtos de qualquer toxicidade, favorecendo o ganho em competitividade para esses produtos.

A própolis é um produto natural proveniente de substâncias (resinas) coletadas das plantas, pelas abelhas, e misturadas com suas secreções. As abelhas modificam a composição original da resina da planta misturando-as com secreções das glândulas hipofaringeais, especialmente $\beta$-glicosidases. Dessa forma, os flavonóides heterosídeos, principais compostos de ação antibacteriana da própolis, são hidrolisados para a forma de agliconas livres, o que aumenta a ação farmacológica destes compostos (Bonhevi et al., 1994; Park \& Ikegaki, 1998).

Objeto de estudo em diversos países, a própolis, subproduto da apicultura, tem demonstrado importantes propriedades terapêuticas, como atividades antimicrobianas, antiinflamatórias e cicatrizantes (Ghisalberti, 1979). Segundo Mirzoeva et al. (1997), a própolis e alguns de seus componentes possuem efeitos sobre a permeabilidade da membrana citopasmática bacteriana aos íons, causando a dissipação do potencial de membrana, o que a caracteriza como substância ionófora. Logo, a atividade antimicrobiana da própolis ocorre pela inibição de bactérias classificadas como gram-positivas (Ghisalberti, 1979; Vargas et al., 1994; Goulart, 1995; Park et al., 1998a; Park et al., 2000).

Foi constatada, recentemente, a inibição do crescimento de bactérias gram-positivas, responsáveis pela incidência de mastite em bovinos leiteiros (Pinto, 2000). Entretanto, não há relatos da aplicabilidade da própolis como aditivo nutricional para ruminantes e de seus efeitos sobre a população microbiana ruminal.

Se a própolis atua sobre as bactérias gram-positivas ruminais, espera-se que sua adição à ração e em cultivos de microrganismos in vitro, assim como ocorre com os ionóforos, iniba o crescimento de bactérias proteolíticas (Hino \& Russell, 1986) e, conseqüentemente, a desaminação e a proteólise (Russell \& Martin, 1984). Em relação à produção de ácidos graxos voláteis, espera-se que ocorra aumento na produção de propionato, com conseqüente redução na relação acetato:propionato no rúmen. A maior proporção de propionato é benéfica, por disponibilizar no rúmen menores quantidades de carbono e hidrogênio que seriam utilizados para a produção de metano. Sabe-se que menor produção de metano é sinônimo de aumento na eficiência energética, com conseqüente melhor desempenho animal. Segundo Lana et al. (1998), a produção de metano pelas bactérias ruminais e intestinais pode corresponder a uma perda energética de até $13 \%$ em relação à energia do alimento ingerido. Essa redução implica ainda na diminuição da poluição ambiental, em virtude de o gás metano ser um dos responsáveis pela destruição da camada de ozônio.

Objetivou-se, neste trabalho, determinar a ação da própolis sobre a desaminação in vitro de aminoácidos e a fermentação ruminal em bovinos recebendo dieta contendo 35\% de concentrado.

\section{Material e Métodos}

O experimento foi realizado no Setor de Bovinos e as análises laboratoriais foram realizadas no Laboratório de Nutrição Animal do Departamento de Zootecnia e no Laboratório de Microbiologia de Anaeróbios do Departamento de Microbiologia da Universidade Federal de Viçosa (UFV), em Viçosa/MG.

A cidade de Viçosa localiza-se na Zona da Mata do Estado de Minas Gerais, a $20^{\circ} 45^{\prime}$ de Latitude Sul e $42^{\circ} 51^{\prime}$ de Longitude Oeste e a altitude de $649 \mathrm{~m}$. De acordo com dados fornecidos pelo Departamento de Engenharia Agrícola da Universidade Federal de Viçosa, o clima de Viçosa é subtropical, com inverno frio e seco e verão quente e úmido, sendo classificado como Cwa subtropical. Apresenta precipitação pluviométrica anual média de $1342 \mathrm{~mm}$, sendo que $80 \%$ das chuvas ocorrem entre os meses de outubro e março, período chuvoso, e os $20 \%$ restantes, entre os meses de abril e setembro, período seco. A temperatura média das máximas é de $26,1^{\circ} \mathrm{C}$; a média das mínimas, de $14^{\circ} \mathrm{C}$; e a umidade relativa do ar, de $80 \%$.

A própolis bruta foi adquirida de uma apicultura instalada na zona rural de Viçosa, safra de primavera. A vegetação de plantas visitadas pelas abelhas é bastante diversificada nessa localidade (Zona da Mata Mineira), o que confere à própolis excelente classificação em qualidade.

Na obtenção do extrato de própolis, foram utilizados

\footnotetext{
R. Bras. Zootec., v.33, n.4, p.1086-1092, 2004
} 
30 g de própolis bruta triturada para cada $100 \mathrm{~mL}$ de solução alcoólica $(99,5$ ou $70,0 \%$, correspondendo às técnicas da extração em etanol e etanol hidratado, respectivamente), por um período de 10 dias. Em seguida, foi feita a filtragem em papel-filtro, obtendo-se a solução-estoque. Foram feitas diluições da soluçãoestoque utilizando-se 0,$0 ; 16,7 ; 33,3 ; 50,0 ; 66,7 ; 83,3$; e $100,0 \%$ da mesma.

Para determinação in vitro da proteína microbiana, do $\mathrm{pH}$, da amônia e atividade específica da produção de amônia (AEPA), foi utilizado o líquido ruminal de um animal recebendo forragem, coletado duas horas após o arraçoamento, filtrado em quatro camadas de gaze e transportado anaerobicamente para o laboratório. Na seqüência, o líquido foi transferido para um erlenmayer e mantido a $39^{\circ} \mathrm{C}$ (anaerobiose), para a separação da fase líquida (contendo bactérias) dos protozoários e das partículas dos alimentos (fases mais densa e o sobrenadante, respectivamente). O inóculo foi obtido da diluição da fase líquida em solução-tampão de McDougall, na proporção de 1:4, em condições anaeróbicas, e então utilizado nas incubações.

As incubações foram feitas em triplicata, sob anaerobiose a $39^{\circ} \mathrm{C}$ em frascos contendo $8,8 \mathrm{~mL}$ do inóculo, $1 \mathrm{~mL}$ de solução contendo $15 \%$ de caseína hidrolisada (trypticase) e 0,2 mL das soluções alcoólicas referidas na obtenção do extrato de própolis, conforme descrito por Lana \& Russel (1997) e Lana et al. (1998). Trypticase foi adicionada à incubação como fonte de aminoácidos para a avaliação da atividade desaminadora da população microbiana.

Foram coletadas amostras do inóculo para determinação de proteína microbiana (Lowry et al., 1951) e amostras dos frascos, nos tempos zero e 4 horas de incubação, para análises de pH e amônia (Chaney \& Marbach, 1962).

A atividade específica de desaminação ou a capacidade das bactérias em desaminar aminoácidos foi calculada em função do diferencial de concentração de amônia nos frascos de incubação entre os tempos zero e quatro horas (mmolar), dividido pela concentração da proteína microbiana no meio de cultura ao início da incubação (mg/L), e então dividido pelo tempo de incubação (minutos), de acordo com Lana \& Russell (1997), conforme o esquema abaixo:

AEPA $(\mathrm{nmol} / \mathrm{mg}$ Proteína $/ \mathrm{min})=\left(\left[\boldsymbol{\Delta} \mathrm{NH}_{3}\right] \mathrm{x}\right.$ 1.000.000) / PTN microb / tempo (min) em que $\left[\boldsymbol{\Delta} \mathrm{NH}_{3}\right]=$ concentração de amônia no tempo quatro horas - concentração de amônia no tempo zero horas $(\mathrm{mM})$; PTN microb. = concentração de proteína microbiana no tempo zero horas $(\mathrm{mg} / \mathrm{L})$

Foram realizadas análises de regressão dos níveis de própolis sobre a atividade de desaminação in vitro.

Um segundo estudo foi realizado com bovinos fistulados. Para determinação in vivo da proteína microbiana, do pH, dos AGVs, da amônia e atividade específica da produção de amônia (AEPA), foram utilizados quatro novilhos Holandeses fistulados no rúmen (480 kg de PV) recebendo dieta $(12,7 \%$ de PB) contendo $65 \%$ de feno de braquiária e $35 \%$ de concentrado (10\% de farelo de soja e 25\% de fubá de milho), fornecida ad libitum, a cada seis horas, para assegurar estabilidade das condições ruminais (Gonçalves, 2001).

O experimento consistiu de dois períodos experimentais de sete dias; no primeiro período foram fornecidos $8 \mathrm{~mL}$ de etanol/animal a cada 6 horas através da fístula ruminal e no segundo, $8 \mathrm{~mL}$ da solução-estoque em etanol 70\%, diluída para 50\% da mesma.

Foi determinado o consumo de matéria seca pelos animais e coletado o líquido ruminal imediatamente antes e duas horas após as alimentações das 6 e 12 horas, nos dias seis e sete de cada período experimental, para análises de amônia, AGVs e pH ruminal.

Para a determinação da AEPA, 800 mL de líquido ruminal foi coletado duas horas após o fornecimento dos alimentos aos animais, e utilizado como fonte de inóculo para a incubação in vitro. A metodologia para a estimativa da AEPA foi similar à descrita no experimento 1, diferenciando-se desta por ser utilizado 9,0 mL de inóculo mais solução-tampão e 1,0 mL de caseína hidrolisada.

As análises de ácidos graxos voláteis foram efetuadas em cromatógrafo de gás, segundo os procedimentos descritos por Barbosa (2000). Assim, as amostras do líquido centrifugado foram diluídas na proporção de $500 \mu \mathrm{l}$ para $500 \mu \mathrm{l}$ de ácido fosfórico (25\%) e novamente centrifugadas a 12.500 g por 20 minutos, até que as alíquotas ficassem totalmente livres de impurezas.

O padrão utilizado para o cálculo das concentrações de ácidos graxos voláteis nas amostras foi preparado da seguinte forma: em um balão volumétrico de $50 \mathrm{~mL}$, completaram-se $50 \mathrm{~mL}$ com ácido fosfórico a 25\% e pipetados, por intermédio de pipeta automática, 
$171 \mu \mathrm{l}$ de ácido acético; $149 \mu \mathrm{l}$ de ácido propiônico; $138 \mu \mathrm{l}$ de ácido butírico; $23 \mu \mathrm{l}$ de ácido isobutírico; $27 \mu \mathrm{l}$ de ácido isovalérico e $27 \mu \mathrm{l}$ de ácido valérico. Essas quantidades foram utilizadas de modo que a concentração final do ácido padrão fosse de 60, 40, 30 e $5 \mathrm{mM}$ dos ácidos acético, propiônico, butírico e demais ácidos, respectivamente.

A coluna utilizada foi a Nukol da Supelco. Os parâmetros do equipamento foram: temperatura inicial de $100^{\circ} \mathrm{C}$ e final de $200^{\circ} \mathrm{C}$ para a coluna, 220 e $240^{\circ} \mathrm{C}$ para o injetor, 250 e $270^{\circ} \mathrm{C}$ para o detector de chama. O modelo para controle foi determinado por split, com uma pressão da coluna de $150 \mathrm{kPA}$, fluxo da coluna de $1,90647 \mathrm{~mL} / \mathrm{min}$, velocidade linear de $43,228 \mathrm{~cm} / \mathrm{s}$, fluxo total de $158 \mathrm{~mL}$, comprimento de $30 \mathrm{~m}$ e diâmetro da coluna de $0,25 \mathrm{~mm}$. Os cálculos foram realizados por intermédio da área em que se adotou o método de normalização correta.

Os dados resultantes do experimento com os animais fistulados foram analisados pelo teste ' $t$ ', para avaliar a diferença entre os dois tratamentos (sem e com adição de extrato de própolis a 70\%). Para a variável 'consumo', foram utilizados quatro animais em dois períodos, totalizando oito unidades experimentais. Para as demais variáveis, o ambiente ruminal em cada tempo de coleta foi considerado a unidade experimental.

\section{Resultados e Discussão}

Os extratos de própolis obtidos por ambas as técnicas (extração em etanol e etanol hidratado) foram eficientes em reduzir a AEPA pela população microbiana ruminal (Figura 1). A extração com 70\% de etanol foi mais eficiente, pois, mesmo quando diluída a 33,3\%, causou os maiores valores de inibição (78\%).

Park et al. (1998b) também observaram maior porcentagem de inibição do crescimento microbiano proporcionado pelos extratos etanólicos de própolis a 60,70 e $80 \%$, com decréscimos nesta atividade nas porcentagens mais altas de etanol (90 e 95\%). Segundo Park et al. (1998) e Woisky \& Salatino (1998), a técnica do etanol hidratado tem apresentado maior poder de extração dos compostos terapêuticos da própolis. Assim, os resultados deste trabalho confirmam a maior eficiência dos extratos com álcool hidratado.

Em trabalhos in vitro, a monensina (5 micro molares) diminuiu de três a 36\% a AEPA, pela população microbiana, quando incubada em um meio contendo 15 g/L de caseína hidrolisada (Chen \& Russell, 1991; Yang \& Russell, 1993), valores inferiores aos observados no presente trabalho.

O efeito da monensina na inibição da produção ruminal de amônia foi inicialmente observado por Dinius et al. (1976). Em experimento com bovinos recebendo feno de gramínea e 0, 1 e $2 \mathrm{~kg}$ de farelo de soja/animal/dia, Yang \& Russell (1993) verificaram que a monensina reduziu de 30 a $54 \%$ o nível ruminal de amônia e de 28 a 38\% a AEPA. Em dietas contendo de $100 \%$ de feno de gramíneas a $100 \%$ de feno de leguminosas, Lana \& Russell (1997) verificaram que a monensina reduziu em até $28 \%$ o nível ruminal de amônia e de 18 a 25\% a AEPA.

Em relação ao trabalho in vivo, não houve efeito de tempo e interação tempo*tratamento sobre o pH e a amônia no rúmen, indicando que houve estabilidade das condições ruminais, ao se fornecer a alimentação aos animais a cada seis horas. Verifica-se, na Tabela 1 , que o extrato de própolis não afetou o consumo de

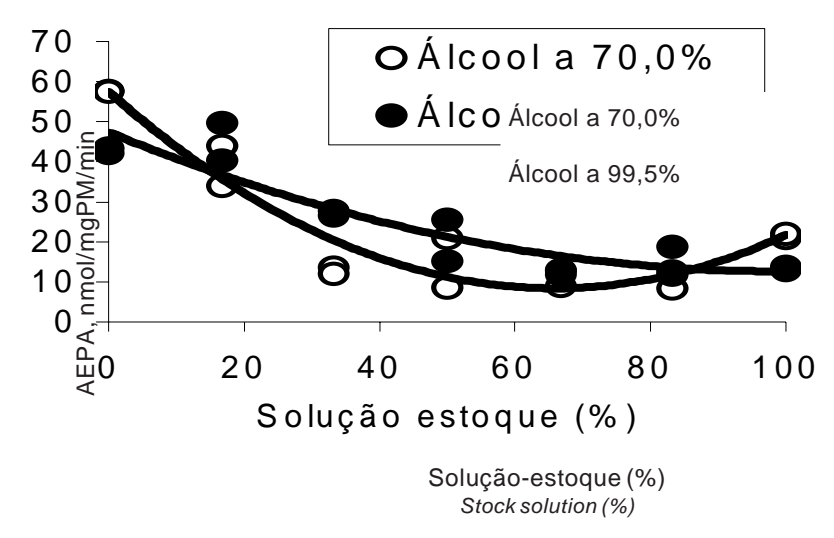

Figura 1 - Efeito de diferentes concentrações de extrato de própolis (solução estoque: $30 \mathrm{~g}$ própolis/ $100 \mathrm{~mL}$ álcool) sobre a atividade específica de produção de amônia ( $\mathrm{nmol} \mathrm{NH}_{3} / \mathrm{mg}$ de proteína microbiana/minuto de incubação). A solução-estoque foi diluída tanto em álcool etílico hidratado a $70 \%$ (o), ou anidro $(99,5 \%, \bullet)$ e incubados sob anaerobiose a $39^{\circ} \mathrm{C}$ em meio contendo $15 \mathrm{~g} / \mathrm{L}$ de caseína hidrolisada (trypticase).

Figure 1 - Effect of different propolis extract concentrations (stock solution, $30 \mathrm{~g}$ propolis/ $100 \mathrm{~mL}$ alcohol) on the specific activity of ammonia production ( $\mathrm{nmol}$ $\mathrm{NH}_{3} / \mathrm{mg}$ of microbial protein/minute of incubation). The stock solution was diluted either in hydrated ethanol $70 \%$ (0), or anhydrous ethanol $(99.5 \%, \bullet)$ and anaerobically incubated at $39^{\circ} \mathrm{C}$ in a media with $15 \mathrm{~g} / \mathrm{L}$ of hydrolyzed casein. 
matéria seca, o pH e a amônia ruminais e a concentração de proteína microbiana no líquido de rúmen (diluído em 1:4 com solução-tampão de McDougall). Entretanto, a própolis inibiu $(\mathrm{P}<0,001)$ a AEPA pelos microrganismos ruminais, indicando que, apesar de não ter reduzido o nível ruminal de amônia, há o potencial deste efeito ocorrer em outras situações, como em dietas contendo alta taxa de proteína degradável/carboidrato fermentescível, como no caso de animais sob pastagens novas de gramíneas ou pastagens de gramíneas consorciadas com leguminosas.

O extrato de própolis não afetou a proporção dos ácidos acético, propiônico e butírico no total de ácidos graxos no líquido ruminal. Entretanto, o extrato de própolis aumentou $(\mathrm{P}<0,001)$ a concentração total de AGVs. Embora não-significativo, o extrato de própolis aumentou em $15 \%$ a relação acetato:propionato, mostrando-se contrário ao observado em estudos que utilizam modificadores da fermentação ruminal, a exemplo de lipídios e ionóforos. O uso desses aditivos, via de regra, resulta em aumentos da concentração molar de propionato no rúmen. Essa alteração molar de propionato no rúmen deve-se principalmente à diminuição da atividade dos microrganismos celulolíticos (digestão de tecidos fibrosos), com conseqüente diminuição nas taxas de renovação ruminal (Van Nevel \& Demyer, 1988; Spears, 1990). Segundo Thornton \& Owens (1981) e Spears (1990), os ionóforos selecionam uma comunidade bacteriana que produz mais propionato e menos acetato e butirato. Portanto, confirmando em novos estudos a ocorrência de aumento da relação acetato:propionato pelo uso da própolis, investigações dos possíveis efeitos benéficos desta sobre a degradação de alimentos fibrosos devem ser realizadas, inclusive com a preocupação de identificar os possíveis compostos químicos da própolis relacionados a essa ação.

Tabela 1 - Efeito do extrato de própolis sobre o consumo de matéria seca (CMS), pH, concentrações de amônia, proteína microbiana e ácidos graxos voláteis (AGV) ruminais, em novilhos, e atividade específica de produção de amônia (AEPA), por microrganismos ruminais

Table 1 - Effect of propolis extract on the dry matter intake (DMI), pH, ammonia concentrations, microbial protein and volatile fatty acids (VFA), in steers, and specific activity of ammonia production (SAAP), by ruminal microorganisms

\begin{tabular}{|c|c|c|c|c|}
\hline \multirow[t]{2}{*}{$\begin{array}{l}\text { Parâmetros } \\
\text { Parameters }\end{array}$} & \multicolumn{2}{|c|}{$\begin{array}{l}\text { Tratamentos } \\
\text { Treatments }\end{array}$} & \multirow[t]{2}{*}{$\begin{array}{l}\text { EPM } \\
\text { SEM }\end{array}$} & \multirow[t]{2}{*}{$\mathrm{P}<$} \\
\hline & $\begin{array}{l}\text { Controle } \\
\text { Control }\end{array}$ & $\begin{array}{l}\text { Própolis } \\
\text { Propolis }\end{array}$ & & \\
\hline CMS (kg/animal/dia) & 10,88 & 10,52 & 1,487 & 0,870 \\
\hline $\begin{array}{l}\text { DMI ( } \mathrm{kg} / \text { animal/day }) \\
\text { pH ruminal } \\
\text { Ruminal pH }\end{array}$ & 6,36 & 6,52 & 0,105 & 0,310 \\
\hline $\begin{array}{l}\text { Amônia ruminal (mM) } \\
\text { Ruminal ammonia (mM) }\end{array}$ & 4,89 & 5,56 & 0,343 & 0,220 \\
\hline $\begin{array}{l}\text { Proteína microbiana }(\mathrm{mg} / \mathrm{L}) \\
\text { Microbial protein }\end{array}$ & 2997,20 & 3076,20 & 194,029 & 0,780 \\
\hline $\begin{array}{l}\text { AEPA (nmol/mg PM/minuto) } \\
\text { SAAP (nmol MP/minute) }\end{array}$ & $11,65 a$ & $8,10 \mathrm{~b}$ & 0,373 & 0,001 \\
\hline $\begin{array}{l}\% \text { Acetato } \\
\% \text { Acetate }\end{array}$ & 72,40 & 74,90 & 1,28 & 0,210 \\
\hline $\begin{array}{l}\text { \% Propionato } \\
\% \text { Propionate }\end{array}$ & 18,00 & 16,20 & 0,92 & 0,220 \\
\hline $\begin{array}{l}\% \text { Butirato } \\
\% \text { Butyrate }\end{array}$ & 9,50 & 8,80 & 0,59 & 0,410 \\
\hline $\begin{array}{l}\text { Relação Acetato:Propionato } \\
\text { Acetate:Propionate ratio }\end{array}$ & 4,06 & 4,68 & 0,89 & 0,210 \\
\hline $\begin{array}{l}\text { AGV total }(\mathrm{mM}) \\
\text { Total VFA }(m M) \\
\end{array}$ & $60,8 a$ & $94,8 b$ & 1,24 & 0,001 \\
\hline
\end{tabular}

R. Bras. Zootec., v.33, n.4, p.1086-1092, 2004 
Tabela 2 - Estimativas das correlações entre tratamento $(0=$ controle; $1=$ própolis), $\mathrm{pH}$ e ácidos graxos voláteis no líquido ruminal ${ }^{1}$

Table 2 - Estimates of the correlations among treatment ( $O=$ control; 1 - propolis), $\mathrm{pH}$ and volatile fatty acids in the ruminal liquid

\begin{tabular}{|c|c|c|c|c|c|c|c|}
\hline $\begin{array}{l}\text { Correlação }^{1} \\
\text { Correlation }^{1}\end{array}$ & $\begin{array}{c}\text { Tratamento } \\
\text { Treatment }\end{array}$ & $\mathrm{pH}$ & $\%$ Ac & $\% \operatorname{Pr}$ & $\%$ But & $\mathrm{AGVt}$ & $A: P$ \\
\hline $\mathrm{pH}$ & 0,42 & & & & & & \\
\hline$\%$ Ac & 0,49 & 0,92 & & & & & \\
\hline \% Pr & $-0,49$ & $-0,93$ & $-0,93$ & & & & \\
\hline$\%$ But & $-0,34$ & $-0,59$ & $-0,79$ & 0,50 & & & \\
\hline $\mathrm{AGVt}$ & 0,94 & 0,32 & 0,41 & $-0,36$ & $-0,38$ & & \\
\hline $\mathrm{A}: \mathrm{P}$ & 0,50 & 0,91 & 0,96 & $-0,99$ & $-0,60$ & 0,37 & \\
\hline AEPA & $-0,94$ & $-0,26$ & $-0,33$ & 0,31 & 0,26 & $-0,84$ & $-0,31$ \\
\hline $\begin{array}{l}1: A C=\text { acet } \\
\text { acetato:prop } \\
\text { AEPA = ativid } \\
1: A C=\text { acetate } \\
\text { SAAP = specific }\end{array}$ & $\mathrm{Pr}=$ propiona & putyrate & butirat & AGVt & $A G V t$ & $A: P=$ & $\begin{array}{l}\text { relaçãc } \\
\text { ratio. }\end{array}$ \\
\hline
\end{tabular}

Na Tabela 2, verifica-se que houve correlação positiva entre o $\mathrm{pH}$ e a concentração de acetato ruminal e a relação acetato:propionato, sendo esta correlação negativa para com a concentração de propionato. A atuação das bactérias formadoras de acetato é favorecida em $\mathrm{pH}$ mais elevado, contrariamente à atuação das formadoras de propionato, que dependem de menores valores de $\mathrm{pH}$ para seu crescimento ótimo. Russell \& Dombrowski(1980)observaram que as bactérias ruminais fibrolíticas Ruminococcus albus, $R$. flavefaciens e Fibrobacter succinogenes, produtoras de acetato, apresentam crescimento parcialmente inibido em pH 6,0-6,1 e completamente inibido em valores de $\mathrm{pH}$ abaixo de 5,9, valores inferiores aos observados no presente trabalho.

Ao contrário do efeito do $\mathrm{pH}$, a própolis não interferiu nas proporções dos AGVs, entretanto, a própolis apresentou alta correlação positiva com a concentração total de AGV e alta correlação negativa com a AEPA, confirmando os resultados apresentados na Tabela 1.

\section{Conclusões}

A própolis foi eficiente em inibir a atividade de desaminação de aminoácidos pelos microrganismos ruminais tanto in vitro quanto in vivo, sendo resultados de grande interesse ao nutricionista de ruminantes, em razão de a proteína ser o nutriente mais oneroso na dieta desses animais, sendo de fundamental valia que parte desse nutriente escape da fermentação pela microbiota ruminal, possibilitando acentuar a melhoria da eficiência produtiva dos ruminantes.

Embora não tenha alterado a proporcionalidade entre os AGVs, a própolis aumentou a concentração total dos mesmos, o que, em linhas gerais, confere aos ruminantes maior possibilidade de se manterem e produzirem a partir de uma mesma dieta.

Há necessidade de mais pesquisas para verificar o efeito da própolis sobre a fermentação ruminal e o desempenho dos animais, bem como a possível ocorrência de sinergismos com os lipídios e ionóforos.

\section{Literatura Citada}

BARBOSA, N.G.S. Fermentação da proteína dos alimentos por microrganismos ruminais in vivo e in vitro em função da acidez, fontes de proteína e ionóforos. Viçosa, MG: Universidade Federal de Viçosa, 2000. 76p. Dissertação (Mestrado em Zootecnia) - Universidade Federal de Viçosa, 2000.

BONVEHI, J.S.; COLL, F.V.; JORDÁ, R.E. The composition, active components and bacteriostatic activity of propolis in dietetics. Journal of American Oil Chemists Society, v.71, n.5, p.529-532, 1994.

CHANEY, A.L.; MARBACH, E.P. Modified reagents for determination of urea and ammonia. Clinical Chemical, v.8, p.130-132, 1962.

CHEN, G.; RUSSELL, J.B. Effect of monensin and a protonophore on protein degradation, peptide accumulation, and deamination by mixed ruminal microorganisms in vitro. Journal of Animal Science, v.69, p.2196-2203, 1991.

DINIUS, D.A.; SIMPSON, M.E.; MARSH, P.B. Effect of monensin fed with forage on digestion and the ruminal ecossystem of steers. Journal of Animal Science, v.42, p.229-234, 1976.

GHISALBERTI, E.L. Propolis: a review. Bee World, v.60, p.59-84, 1979.

GONÇALVES, A.L.; LANA, R.P.; RODRIGUES, M.T. et al. Padrão nictemeral do $\mathrm{pH}$ ruminal e comportamento alimentar

R. Bras. Zootec., v.33, n.4, p.1086-1092, 2004 
de cabras leiteiras alimentadas com dietas contendo diferentes relações volumoso:concentrado. Revista Brasileira de Zootecnia, v.30, n.6, p.1886-1892, 2001.

GOULART, C.S. Estudos preliminares sobre atividade "in vitro" do extrato etanólico de própolis (EEP) no combate a bactérias isoladas de processos infecciosos de animais. Salvador: Universidade Federal da Bahia, 1995. 18p. Monografia (Graduação em Zootecnia) - Universidade Federal da Bahia, 1995.

HINO, T.; RUSSELL, J.B. Relative contributions of ruminal bacteria and protozoa to the degradation of protein in vitro. Journal of Animal Science, v.64, p.261-270, 1986.

LANA, R.P.; RUSSELL, J.B. Effect of forage quality and monensin on the ruminal fermentation of fistulated cows fed continuously at a constant intake. Journal of Animal Science, v.75, p.224-229, 1997.

LANA, R.P.; RUSSELL, J.B.; Van AMBURGH, M.E. The role of $\mathrm{pH}$ in regulating ruminal methane and ammonia production. Journal of Animal Science, v.76, p.2190-2196, 1998.

LOWRY, O.H.; ROSEBROUGH, N.J.; FARR, A.L. et al. Protein measurement with the Folin phenol reagent. Journal of Biological Chemistry, v.193, p.265-275, 1951.

MIRZOEVA, O.K.; GRISHANIN, R.N.; CALDER, P.C. Antimicrobial action of propolis and some of its components: the effects on growth, membrane potencial and motility of bacteria. Microbiology Research, v.152, n.3, p.239-246, 1997.

PARK, Y.K.; KOO, H.; IKEGAKI, M. et al. Effect of propolis on Streptococcus mutans, Actinomyces naeslundii and Staphylococcus aureus. Revista Microbiologia, v.29, p.143148, 1998a.

PARK, Y.K.; IKEGAKI, M. Preparation of water and ethanolic extracts of propolis and evaluation of the preparations. Bioscience Biotechnology and Biochemistry, v.62, n.11, p.2230-2232, 1998b.

PARK, Y.K.; IKEGAKI, M.; ALENCAR, S.M. Classificação das própolis brasileira a partir de suas características físicoquímicas e propriedades biológicas. Mensagem Doce, v.58, n.9, p.2-7, 2000.

PINTO, M.S. Efeito antimicrobiano de própolis verde do Estado de Minas Gerais sobre bactérias isoladas do leite de vacas com mastite. Viçosa, MG: Universidade Federal de Viçosa, 2000. 92p. Dissertação (Mestrado em Medicina Veterinária) - Universidade Federal de Viçosa, 2000.
RUSSELL, J.B.; DOMBROWSKI, D.B. Effect of $\mathrm{pH}$ on the efficiency of growth by pure cultures of rumen bacteria in continuous culture. Applied Environmental Microbiology, v.39, p.604-610, 1980.

RUSSELL, J.B.; MARTIN, S.A. Effects of various methane inhibitors on the fermentation of amino acids by mixed rumen microorganisms in vitro. Journal of Animal Science, v.59, p.1329-1338, 1984.

SPEARS, J.W. Ionophores and nutrient digestion and absorption in ruminants. Journal of Nutrition, v.120, p.632-638, 1990.

THORNTON, J.H.; OWENS, F.N. Monensin supplementation and in vivo methane production by steers. Journal of Animal Science, v.52, n.3, p.628-634, 1981.

Van NEVEL, C.J.; DEMEYER, D.I. Manipulation of rumen fermentation. In: HOBSON, P.N. (Ed.) The rumen microbial ecosystem. London: Elsevier Applied Animal Science, 1988. p.285-322.

VARGAS, A.C.; POCAI, E.A.; FONTANA, F.Z. et al. Dados parciais do teste "in vitro" da atividade antibacteriana da própolis. In: CONGRESSO DE MEDICINA VETERINÁRIA DO CONE SUL, 1.; CONGRESSO ESTADUAL DE MEDICINA VETERINÁRIA, 12., 1994, Porto Alegre. Anais... Porto Alegre: SOVERGS, 1994. 160p.

WOISKY, R.G.; SALATINO, A. Analysis of propolis: some parameters and procedures for chemical quality control. Journal of Apicultural Research, v.37, p.99-105, 1998.

YANG, C.-M.J.; RUSSELL, J.B. Effect of monensin on the specific activity of ammonia production by ruminal bacteria and disappearance of amino nitrogen from the rumen. Applied Environmental Microbiology, v.59, p.3250-3254, 1993.
Recebido em: 18/02/03 Aceito em: 25/09/03 